Pak. J. Agri. Sci., Vol. 53(3), 625-632; 2016

ISSN (Print) 0552-9034, ISSN (Online) 2076-0906

DOI:10.21162/PAKJAS/16.3443

http://www.pakjas.com.pk

\title{
EFFECTS OF SEEDING DEPTH ON SUBCROWN INTERNODE ELONGATION AND GRAIN YIELD IN WHEAT
}

\author{
Lingan Kong,*, Mingze Sun ${ }^{1,2}$ and Fahong Wang ${ }^{1}$ \\ ${ }^{1}$ Crop Research Institute, Shandong Academy of Agricultural Sciences, 202 Gongyebei Road, \\ Jinan 250100, China; ${ }^{2}$ Plant Protection Station of Liaocheng City, Liaocheng 252000, China. \\ "Corresponding author's e-mail: kongling-an@163.com
}

\begin{abstract}
Successful stand establishment is prerequisite for optimum crop yields and can be affected by seeding depth. A field experiment was conducted to investigate the effects of seeding depth on agronomical characteristics, structural feature of subcrown internode (SCI), plant growth and ultimately grain yield of winter wheat. Seeds of Luyuan 502 were sown at four seeding depths $(10,25,40$ and $55 \mathrm{~mm})$. The results showed that increasing the seeding depth from 10 to $40 \mathrm{~mm}$ increased seedling emergence rate, numbers of fall tillers per unit area and per plant. Seeding at 55-mm depth significantly decreased the seedling emergence, tillering capacity, spikes per unit $\mathrm{m}^{2}$; however, the fertile tiller percentage significantly increased compared with shallower seeding. At 10-mm soil depth, there was no SCI produced; at 25 to $55-\mathrm{mm}$ soil depth, the length of SCI increased with increasing of depth. However, the diameter of SCI and diameter and wall thickness of SCI xylem vessel decreased. Regarding hormonal concentration in SCI, $\mathrm{GA}_{3}$ and IAA increased with increasing seeding depth, whereas the maximum ZR and ABA contents were observed at 40-mm soil depth. Similarly, the maximum rate of oxygen consumption was also observed in SCI of 40-mm-sown plants. Transmission electron microscope observations showed many mitochondria in the companion cell (CC) and many plasmodesma connecting CC and sieve element. As the seeding depth increased, values of the normalized difference vegetative index and shoot dry matter weight decreased but interestingly, the highest grain yield was obtained in 40-mm-sown wheat, followed immediately by that at $55-\mathrm{mm}$ depth. It is concluded that wheat sown at about 40-mm soil depth may be optimal for winter wheat growth and production in northern China.

Keywords: Hormone, seeding depth, subcrown internode, ultrastructure, wheat

Abbreviations: ABA, abscisic acid; CC, companion cell; ELISA, enzyme-linked immunosorbent assay; NDVI, normalized difference vegetative index; SCI, subcrown internode; SEM, Scanning electron Microscopy. SPB, sodium phosphate buffer; TEM, transmission electron microscopy; ZR, zeatin riboside.
\end{abstract}

\section{INTRODUCTION}

The subcrown internode (SCI; the basal first internode) of some cereal genotypes produced and rapidly elongated when seeding at depth, setting the crown for a given position and promoting the shoots to reach the soil surface (Huang and Taylor, 1993). However, excessively deep seeding will result in SCI with a length not long enough to send the shoot coming out the soil surface and therefore would reduce the plant stand and yield (Rebetzke et al., 2007).

A large number of reports are available discussing seedling emergence and the responses of SCI development to deep seeding conditions in wheat (Schillinger et al., 1998; Rebetzke et al., 2007) and strong evidence is emerging to support the idea that hormones may promote the expansion of some organs. Ethylene, for example, could stimulate SCI and coleoptile elongation and therefore help the emergence of seedlings to the soil surface; inhibition of ethylene action by carbon dioxide depressed SCI elongation (Suge et al., 1997; Nishizawa et al., 1998). Endogenous GA synthesis was crucial for mesocotyl elongation in maize via cell elongation
(Zhao et al., 2010). The interactions between $\mathrm{GA}_{3}$ and ethylene have also been observed in SCI elongation of wheat (Chen et al., 2001). In deep water rice, a reduction in the level of $\mathrm{ABA}$ due to ethylene treatment is associated with the stimulation of extension growth (Hoffmann-Benning and Kende, 1992; Kende et al., 1998); however, this mechanism may not occur in wheat (Hoffmann-Benning and Kende, 1992). The role of some hormones in regulation of SCI elongation has not well understood and controversy still exist for the role of auxin, cytokinin and ABA in this process.

Deep seeding increased the length of the SCI but decreased the effective xylem radius in barley (Hordeum vulgare) and perennial grasses (Irvine and Therrien, 1985; Redmann and Qi, 1992), while longer SCI and coleoptiles contributed to a higher tolerance to deep-seeding (Takeda and Takahashi, 1999) and were associated with higher levels of winter survival (Ashraf and Taylor, 1974; Loeppky et al., 1989). In addition to the promotion of the plant establishment, appropriate seeding depth with proper length of SCI could affect the transport efficiency of water and mineral nutrients and control the transport from source to sink and therefore 
playing an important role in plant growth and yield formation (Rebetzke et al., 2007; Yagmur and Kaydan, 2009). On the other hand, shallow-seeded seeds do not elongate a SCI and the nutrients are directly transported to the aerial part. Thus, another question may remain to be elucidated that whether the direct transportation has an advantage over that partially through the additional SCI; otherwise, how long of the SCI is optimal for wheat growth and productivity; all of these events are not well understood.

The primary objective of this study was to determine the relationship between SCI length and hormone contents and to assess the influence of seeding depth on seedling emergence and growth in wheat. This information will be valuable for understanding the mechanism of SCI elongation and the growth and grain yield of wheat under different soil depths.

\section{MATERIALSAND METHODS}

The experiment was carried out during the winter wheat growing seasons of 2013-2014 at an experimental station $\left(36^{\circ} 42^{\prime} \mathrm{N}, 117^{\circ} 4^{\prime} \mathrm{E}\right.$; altitude $\left.48 \mathrm{~m}\right)$ of the Shandong Academy of Agricultural Sciences, China. The climate in this region is continental and warm, with an average annual temperature of $13.6^{\circ} \mathrm{C}$ and an average rainfall of $600 \mathrm{~mm}$. The soil type is classified as sandy loam with a $\mathrm{pH}$ of 7.2. The top $40 \mathrm{~cm}$ of soil contained $2.13 \%$ organic matter, $66.2 \mathrm{mg}$ $\mathrm{kg}^{-1}$ of water-hydrolysable nitrogen, $25.3 \mathrm{mg} \mathrm{kg}^{-1}$ of rapidly available phosphorous and $152.4 \mathrm{mg} \mathrm{kg}^{-1}$ of rapidly available potassium.

The seeds of winter wheat cultivar Luyuan 502 were sown to seeding depths of 10,25, 40 and $55 \mathrm{~mm}$ using a seeding rate of $150 \mathrm{~kg} \mathrm{ha}^{-1}$. The distance between the seed rows was 20 $\mathrm{cm}$. Seeding depth was determined by measuring more than ten excavated seedlings from seed remnant to soil surface. Each treatment was replicated three times.

Assessment of agronomical characteristics: The number of emerged seedlings was counted 14 days after sowing (DAS) when no further emergence occurred. For the assessment of the length of the SCI, twenty plants per replication were selected randomly during 12-33 days after sowing. The length of SCI was determined by measuring the distance from the seed to the center of the crown node. Tillers were counted in four rows (each $1 \mathrm{~m}$ long) in each plot at the tillering cessation (Zadoks Stage 25) in fall and again the following spring (Zadoks Stage 27). Number of tillers was expressed as tillers per plant and per $\mathrm{m}^{2}$. Tiller was scored as fertile when it headed and produced five or more grains. Fertile tiller percentage was determined at Zadoks Stage 85 of growth and calculated as the ratio of fertile tillers to the number of tillers counted at Zadoks Stage 27.

Scanning electron microscopy: The mid-portions of the SCI of 22-day old seedlings were cut into 2-mm long sections and were fixed in $2.5 \%$ glutaraldehyde solution in $100-\mathrm{mM}$ sodium phosphate buffer $(\mathrm{pH} 7.2)$ for more than $24 \mathrm{~h}$, dehydrated in a graded ascending series of ethanol, and critical-dried in a $\mathrm{CO}_{2}$ atmosphere. The samples were mounted on aluminium stubs and were then sputtered with gold. The anatomy of SCI cross section was observed using a KYKY-1000B scanning electron microscopy (SEM) (KYKY-1000B, Philips, Eindhoven, The Netherlands). The SCI diameter, the diameter and wall thickness of xylem vessels were measured from the SEM images of the samples. Each value represents the mean of at least eight measurements.

Measurement of endogenous hormone content: The endogenous hormone content was determined using an indirect ELISA (enzyme-linked immunosorbent assay) according to the method of Yang et al. (2001). About $0.5 \mathrm{~g}$ (FW) of SCI of 22-d old seedlings were harvested and ground in an ice-cooled mortar containing $10 \mathrm{ml}$ of $80 \%$ cold acetone and $1 \mathrm{mM}$ butylated hydroxytoluence as an antioxidant. The extract was incubated at $4^{\circ} \mathrm{C}$ for $4 \mathrm{~h}$ and centrifuged at 1000 $\mathrm{g}$ for $20 \mathrm{~min}$ at the same temperature. The supernatant was used to determine the endogenous contents of $\mathrm{GA}_{3}$, IAA, zeatin riboside $(\mathrm{ZR})$ and $\mathrm{ABA}$. Each hormone was assayed in triplicate. Hormone contents were expressed as $\mathrm{ng} \mathrm{g}^{-1} \mathrm{FW}$.

Measurement of respiration activity: Respiration activity was measured as the rate of oxygen consumption in liquid phase using a Clark $\mathrm{O}_{2}$ electrode (Hansatech, Cambridge, UK). The samples of SCI ( $25 \mathrm{mg})$ were cut into small sections and suspended in double distilled $\mathrm{H}_{2} \mathrm{O}$ in the electrode chamber and covered with a dark lid. Samples were continuously mixed with a magnetic stirrer for homogenization of gas in the chamber. Oxygen consumption was measured for a period of $10 \mathrm{~min}$ at $25^{\circ} \mathrm{C}$. The rate of oxygen consumption was expressed as $\mu \mathrm{mol} \mathrm{O}{ }_{2} \mathrm{~min}^{-1} \mathrm{~g}^{-1}$ fresh weight (FW). Data were averaged from five measurements.

Light and transmission electron microscopy: Samples of five SCI of 33-d-old seedlings were collected randomly from five plants. The middle portion of each collected sample was cut into $1 \mathrm{~mm}^{3}$ sections, immediately fixed in $2.5 \%$ glutaraldehyde solution in $100 \mathrm{mM}$ sodium phosphate buffer (SPB) ( $\mathrm{pH} 7.2$ ) for $24 \mathrm{~h}$. After washing with $100 \mathrm{mM} \mathrm{SPB}$, the samples were post-fixed with $1 \%(\mathrm{w} / \mathrm{v})$ osmium tetroxide in SPB at $4^{\circ} \mathrm{C}$ for $2 \mathrm{~h}$. The samples were then dehydrated in an ethanol series, transferred into propylene oxide and finally embedded in Epon812 (Shell Chemical, Houston, TX, USA). Ultrathin sections were cut with an LKB-V microtome and then mounted on a formvar-coated brass grid. The sections were stained with $2 \%$ uranyl acetate $(\mathrm{w} / \mathrm{v})$ in $70 \%$ methanol (v/v) and $0.5 \%$ lead citrate. The preparations were observed under a JEM-1230 transmission electron microscopy (JEOL Ltd., Tokyo, Japan) at $80 \mathrm{kV}$.

Determination of normalized difference vegetative index (NDVI): The NDVI values were measured using a GreenSeeker HandHeld optical sensor (NTech Industries, Inc., Ukiah, CA, USA) at greening, erecting, shooting, booting, anthesis, milking-development, and dough- 
development stages. The sensor was held parallel to the soil, about $60 \mathrm{~cm}$ above the crop canopy. In measuring a plot, the trigger was kept down for 4-5 second so that 12 single counts were collected. The NDVI values of these counts were then averaged to obtain a mean value for each plot. Four measurements were taken from each plot and averaged for statistical analysis.

Shoot dry weight: Wheat dry matter accumulation of shoot parts was determined at erecting, shooting, booting, anthesis, milking-development, dough-development and ripening stages. Two samples (each $0.5 \mathrm{~m}^{2}$ ) of wheat shoots were collected per plot by cutting the seedlings above the soil surface and were dried in a fan-aided oven at $105^{\circ} \mathrm{C}$ for $1 \mathrm{~h}$ and then at $70^{\circ} \mathrm{C}$ up to a constant weight.

Gain mass: Grain mass was measured at 8, 16, 24 and 32 days after anthesis (DAA) by hand-harvesting about 400 spikes of each plot. The harvested spikes were oven dried at $70^{\circ} \mathrm{C}$ for $24 \mathrm{~h}$ and then hand threshed. The amount of grain weight from each treatment was recorded.

Statistical analysis: The statistical analysis was performed using Data Processing System (DPS) statistical software (v.14.10, Refine Information Tech. Co., Ltd., Hangzhou, Zhejiang, China) (Tang and Zhang 2013). One-way ANOVA $(P<0.05)$ was used to detect differences between means. Treatment means were compared by the least significant difference of Tukey's test at $P<0.05$. The data are presented as mean \pm standard deviation and significant differences among treatments are shown by different letters.

\section{RESULTS}

Emergence and tillering: The seeding depth had a significant impact on final emergence of seeds (Table 1). Emergence percentage increased with seeding depths up to $40 \mathrm{~mm}$ (from $79.33 \%$ to $84.00 \%$ ); however, when seeds were sown at depths of $55 \mathrm{~mm}$, the emergence potential was significantly reduced $(P<0.05)$. At the same time, seeding at $55 \mathrm{~mm}$ delayed emergence percentage by 1-2 days. Similarly, increasing seeding depth from 10 to $40 \mathrm{~mm}$ soil greatly increased the rate of tillering in fall and the following spring, but seeding at 55-mm soil depth reduced the fall tiller number per $\mathrm{m}^{2}$ per plant, and reduced the maximum tiller number per $\mathrm{m}^{2}$ at the shooting stage.
Number of spikes per unit area is an important character in agronomic parameter. At 10 to $40-\mathrm{mm}$ soil depth, no significant difference in number of spikes $\mathrm{m}^{-2}$ was observed. However, wheat plants raised from seeds sown at 55-mm soil depth produced significantly less number of spikes $\mathrm{m}^{-2}$ but a significant increase in the fertile tiller percentage, $11.22 \%$ higher than that at $40 \mathrm{~mm}$ soil depth (Table 1).

SCI elongation: Wheat seeds sown at $10-\mathrm{mm}$ depth did not develop the SCI. However, SCI length increased as the seeding depth increased from 25 to $55 \mathrm{~mm}$ (Fig. 1). The SCI has been fully elongated at 33 DAS and wheat plants from shallow seed placement $(25 \mathrm{~mm})$ had a SCI length of $12.2 \mathrm{~mm}$ while SCI length of wheat plants from deeper seed placement $(55 \mathrm{~mm})$ reached approximately $32.8 \mathrm{~mm}$.
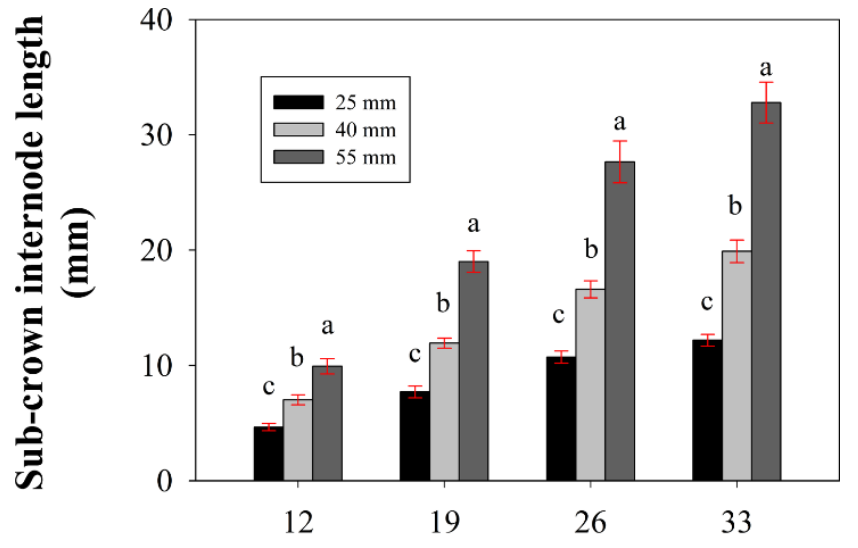

Days after seeding

Figure 1. A time-course study of the SCI elongation in wheat at different seeding depth. Data show the mean values of 20 SCIs with SD (vertical bars).

Anatomical features of SCI: Cross-section of the SCI contains two layers of epidermis cells, 4-5 layers of ground parenchyma and 13-17 vascular strands (Fig. 2).

Diameter of the SCI decreased with the increase of seeding depths (from $1.02 \mathrm{~mm}$ in $25-\mathrm{mm}$-sown plants to $0.96-\mathrm{mm}$ in 40-mm-sown plants and to $0.78 \mathrm{~mm}$ in $55-\mathrm{mm}$-sown plants). No significant effect of seeding depth on the number of vascular bundles occurred. However, the diameter and wall thickness of xylem vessels differed significantly for plants at

Table l. Effects of seeding depth on the agronomic parameters of wheat.

\begin{tabular}{lcccccccc}
\hline $\begin{array}{l}\text { Seeding } \\
\text { depth } \\
(\mathbf{m m})\end{array}$ & $\begin{array}{c}\text { Emergence } \\
\text { count }\left(\mathbf{m}^{-2}\right)\end{array}$ & $\begin{array}{c}\text { Emergence } \\
\text { rate }(\boldsymbol{\%})\end{array}$ & $\begin{array}{c}\text { Fall tillers } \\
\left(\mathbf{m}^{-\mathbf{2}}\right)\end{array}$ & $\begin{array}{c}\text { Fall tillers } \\
\text { per plant }\end{array}$ & $\begin{array}{c}\text { Tillers at } \\
\text { the shooting } \\
\text { stage }\left(\mathbf{m}^{-2}\right)\end{array}$ & $\begin{array}{c}\text { Tillers per } \\
\text { plant at the } \\
\text { shooting stage }\end{array}$ & $\begin{array}{c}\text { Spikes } \\
\left(\mathbf{m}^{-2}\right)\end{array}$ & $\begin{array}{c}\text { Fertile } \\
\text { percentage } \\
(\%)\end{array}$ \\
\hline 10 & $270.45 \mathrm{ab}$ & $79.33 \mathrm{ab}$ & $836.36 \mathrm{c}$ & $3.09 \mathrm{~b}$ & $1442.18 \mathrm{a}$ & $5.33 \mathrm{a}$ & $602.73 \mathrm{a}$ & $41.79 \mathrm{~b}$ \\
25 & $281.82 \mathrm{a}$ & $82.67 \mathrm{a}$ & $898.48 \mathrm{~b}$ & $3.19 \mathrm{ab}$ & $1459.64 \mathrm{a}$ & $5.18 \mathrm{a}$ & $609.09 \mathrm{a}$ & $41.73 \mathrm{~b}$ \\
40 & $286.36 \mathrm{a}$ & $84.00 \mathrm{a}$ & $986.36 \mathrm{a}$ & $3.44 \mathrm{a}$ & $1438.91 \mathrm{a}$ & $5.02 \mathrm{a}$ & $603.94 \mathrm{a}$ & $41.97 \mathrm{~b}$ \\
55 & $253.41 \mathrm{~b}$ & $74.33 \mathrm{~b}$ & $665.15 \mathrm{~d}$ & $2.62 \mathrm{c}$ & $1157.45 \mathrm{~b}$ & $4.57 \mathrm{~b}$ & $540.30 \mathrm{~b}$ & $46.68 \mathrm{a}$ \\
\hline
\end{tabular}

Values are means \pm SD. Significant difference between data was compared by Tukey-test at the 5\% level. Data sharing the same letter were not significantly different. 
different seeding depths. As the seeding depth increased from 25 to $55 \mathrm{~mm}$, the vessel diameter decreased from 28.7 to 25.6 and to $23.8 \mu \mathrm{m}$ and the wall thickness reduced from 1.46 to 1.42 and to $1.21 \mu \mathrm{m}$.

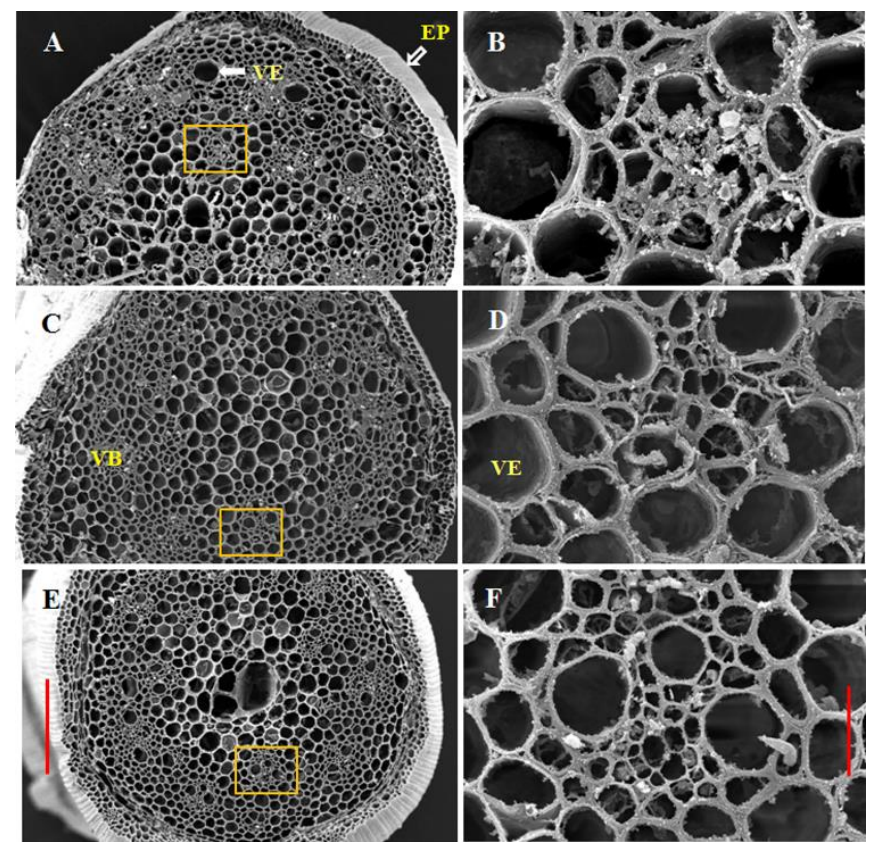

Figure 2. Anatomical features of the middle part of a SCI in wheat at 25- $(\mathrm{A}, \mathrm{B}), \mathbf{4 0 -}(\mathrm{C}, \mathrm{D})$ and 55-mm $(\mathrm{E}$, F) depths. Scanning electron microscope (SEM) images showed that the vessel diameter and wall thickness decreased as the seeding depth increased. (B), (D) and (F): higher magnification of the area highlighted in $(\mathrm{A}),(\mathrm{C})$ and $(\mathrm{E})$, respectively. EP: epidermis; VB: vascular bundle; VE: vessel. Bars: (E), $200 \mu \mathrm{m}$; (F), $30 \mu \mathrm{m}$.

Endogenous hormonal level: The levels of endogenous SCI hormones at 22 DAS showed that ABA and ZR content of wheat SCI at 40-mm depth was significantly greater than that at 55-mm depth, and the latter was then significantly greater than that at 25-mm depth (Fig. 3). The $\mathrm{GA}_{3}$ content increased as the seeding depth increased $(P<0.05)$. Similar results were also observed for IAA content but the difference between wheat plants at 40- and 55-mm depth was not significant.

SCI oxygen consumption rate: During 12 to $19 \mathrm{DAS}$, the rate of SCI oxygen consumption showed increases for four treatments and reached the highest values of $0.16,0.18$ and $0.12 \mu \mathrm{mol} \mathrm{min}{ }^{-1} \mathrm{~g} \mathrm{FW}$, respectively, at $19 \mathrm{DAS}$. Afterwards, it gradually declined (Fig. 4). At 12 DAS, SCI at 25-mm and 55-mm soil depth showed a similar rate of oxygen consumption but both significantly lower than that at $40-\mathrm{mm}$ soil depth. During 19 to 33 DAS, the rate was similar at 25and 40-mm depth but both were significantly higher than that at 55-mm depth.
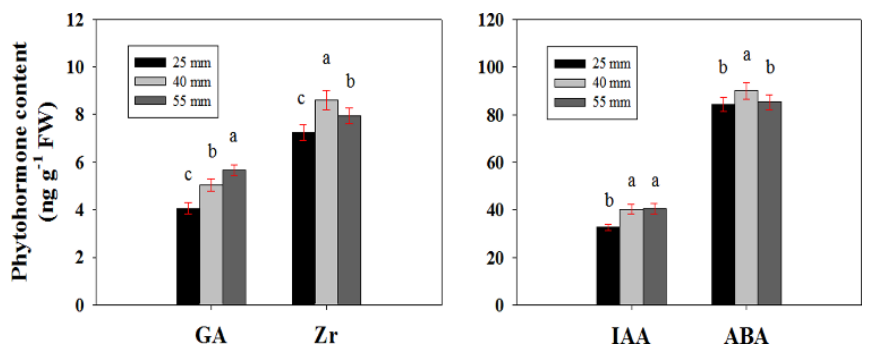

Figure 3. Hormone contents of SCI in wheat at different seeding depth.

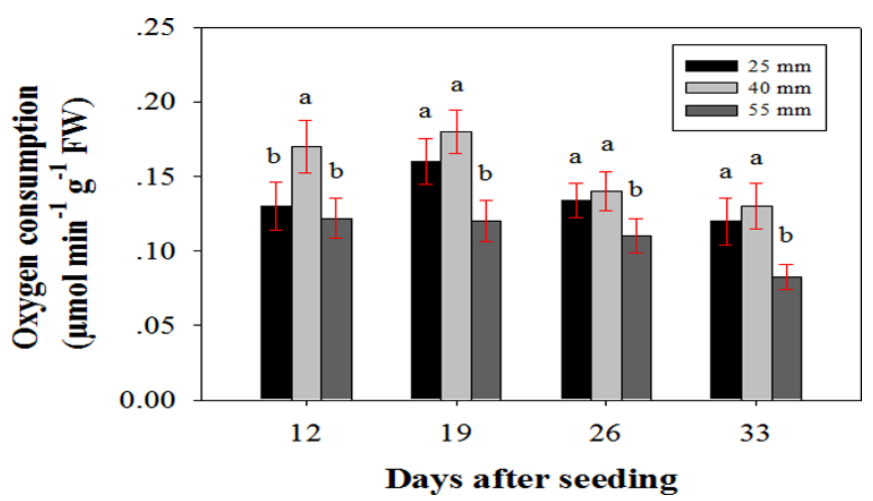

Figure 4. Temporal changes in the rate of SCI oxygen consumption at the elongation stages. Each value represented the average of six experiments.

Ultrastructural features of sieve element/companion cell complex: Transmission electron microscopy (TEM) observation revealed that $\mathrm{CCs}$ were densely cytoplasmic, with the nucleus occupied a relatively large portion, vacuoles and many mitochondria, endoplasmic reticulum, golgi apparatus, and plastid. Abundant plasmodesmata were found connecting $\mathrm{CC}$ with sieve element. It was worth note that a longitudinal structure similar to the sieve plate in sieve element was observed, through which the transportation of protein or other large molecules might occur (Fig. 5A and B).

NDVI and shoot dry weight: As the plants grew, the NDVI gradually increased in different treatments, and reached the peak at the booting stage. After that, these values gradually decreased (Table 2). Significant difference in NDVI occurred between 55-mm-sown plants and shallow depths (10, 25 and $40 \mathrm{~mm})(P<0.05)$. However, the difference was gradually declined and thus the NDVI values in 55-mm-sown wheat showed no difference from that at the 25- and 40-mm depth during the grain filling period.

As the plants developed, the shoot dry weight increased in wheat under different depth conditions. Generally, the shoot dry weight decreased as the seeding depth increased during the measuring period and was significantly lower in wheat at $55-\mathrm{mm}$ depth than that at shallower depth $(10,25$ and $40 \mathrm{~mm})$ $(P<0.05)$. Similarly, the shoot dry weight at $40-\mathrm{mm}$ depth was also significantly lower than that at depth 10 -and at some stages at $25-\mathrm{mm}$ soil depth $(P<0.05)$ (Table 2$)$. 
Table 2. Normalized difference vegetative index (NDVI) and shoot dry weight in wheat under different seeding depths.

\begin{tabular}{|c|c|c|c|c|c|}
\hline \multirow{2}{*}{ Parameters } & \multirow{2}{*}{ Growth Stage } & \multicolumn{4}{|c|}{ Sowing depth (mm) } \\
\hline & & 10 & 25 & 40 & 55 \\
\hline \multirow[t]{7}{*}{ NDVI } & Greening & $0.59 \pm 0.02 \mathrm{a}$ & $0.57 \pm 0.02 \mathrm{a}$ & $0.60 \pm 0.02 \mathrm{a}$ & $0.52 \pm 0.01 b$ \\
\hline & Erecting & $0.72 \pm 0.02 \mathrm{a}$ & $0.70 \pm 0.02 \mathrm{a}$ & $0.72 \pm 0.012 \mathrm{a}$ & $0.65 \pm 0.01 b$ \\
\hline & Jointing & $0.76 \pm 0.01 \mathrm{a}$ & $0.75 \pm 0.02 \mathrm{a}$ & $0.73 \pm 0.012 \mathrm{ab}$ & $0.70 \pm 0.01 b$ \\
\hline & Booting & $0.80 \pm 0.02 \mathrm{a}$ & $0.79 \pm 0.02 \mathrm{ab}$ & $0.79 \pm 0.02 \mathrm{ab}$ & $0.76 \pm 0.02 b$ \\
\hline & Anthesis & $0.76 \pm 0.01 a$ & $0.76 \pm 0.01 \mathrm{ab}$ & $0.76 \pm 0.02 \mathrm{ab}$ & $0.73 \pm 0.01 b$ \\
\hline & Milking & $0.72 \pm 0.01 \mathrm{a}$ & $0.72 \pm 0.01 \mathrm{a}$ & $0.72 \pm 0.01 \mathrm{a}$ & $0.70 \pm 0.013 a$ \\
\hline & Dough & $0.60 \pm 0.01 \mathrm{a}$ & $0.58 \pm 0.01 \mathrm{a}$ & $0.58 \pm 0.01 \mathrm{a}$ & $0.58 \pm 0.01 \mathrm{a}$ \\
\hline & Erecting & $0.49 \pm 0.021 \mathrm{a}$ & $0.48 \pm 0.016 \mathrm{a}$ & $0.42 \pm 0.02 b$ & $0.32 \pm 0.02 \mathrm{c}$ \\
\hline \multirow[t]{6}{*}{$\left(\mathrm{kg} \mathrm{m}^{-2}\right)$} & Jointing & $0.87 \pm 0.021 a$ & $0.84 \pm 0.02 \mathrm{ab}$ & $0.80 \pm 0.02 b$ & $0.73 \pm 0.02 c$ \\
\hline & Booting & $1.30 \pm 0.021 \mathrm{a}$ & $1.26 \pm 0.03 \mathrm{ab}$ & $1.22 \pm 0.02 b$ & $1.10 \pm 0.03 \mathrm{c}$ \\
\hline & Anthesis & $1.90 \pm 0.04 \mathrm{a}$ & $1.81 \pm 0.05 \mathrm{ab}$ & $1.71 \pm 0.05 b$ & $1.51 \pm 0.04 c$ \\
\hline & Milking & $2.11 \pm 0.06 \mathrm{a}$ & $1.98 \pm 0.06 \mathrm{ab}$ & $1.93 \pm 0.05 b c$ & $1.79 \pm 0.04 \mathrm{c}$ \\
\hline & Dough & $2.23 \pm 0.061 \mathrm{a}$ & $2.16 \pm 0.06 \mathrm{a}$ & $2.13 \pm 0.066 a$ & $1.93 \pm 0.06 b$ \\
\hline & Ripening & $2.34 \pm 0.051 \mathrm{a}$ & $2.24 \pm 0.07 \mathrm{ab}$ & $2.23 \pm 0.07 \mathrm{ab}$ & $2.07 \pm 0.07 b$ \\
\hline \multicolumn{2}{|c|}{ Increase from anthesis to ripening stage $(\%)$} & $23.82 \pm 2.34 \mathrm{a}$ & $23.90 \pm 2.49 b$ & $30.00 \pm 3.69 \mathrm{c}$ & $37.15 \pm 2.55 \mathrm{c}$ \\
\hline
\end{tabular}

Values are means \pm SD of 6 measurements. Significant difference between data was compared by Tukey-test at the 5\% level. Data in rows sharing the same letter were not significantly different.

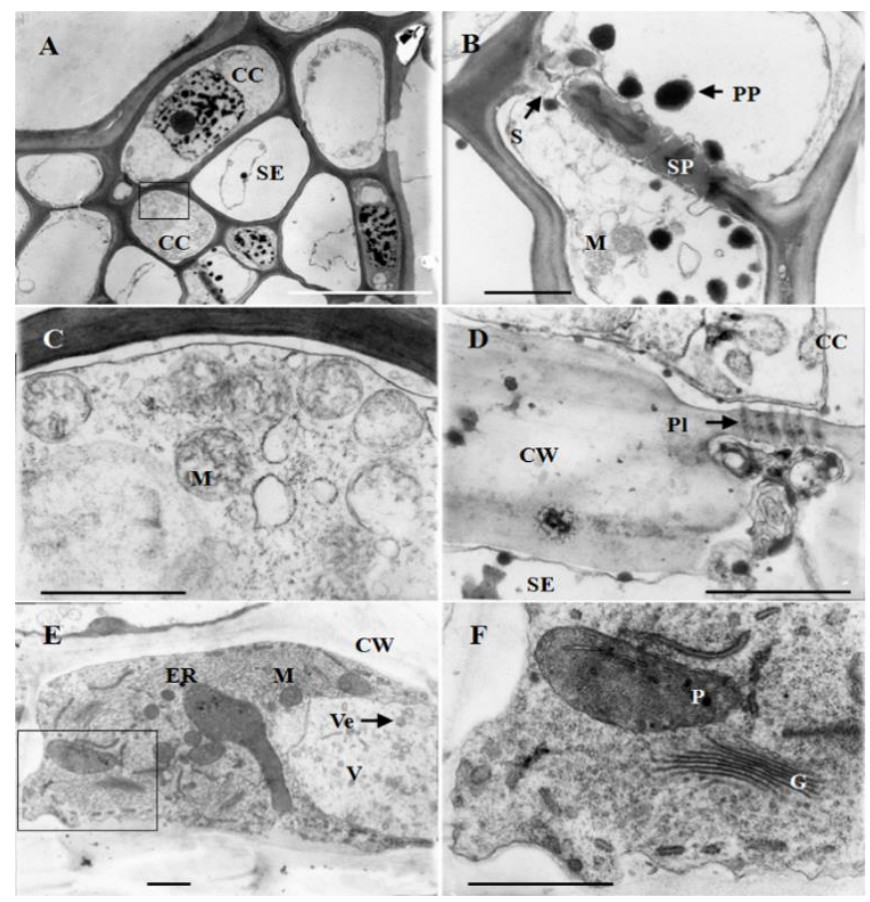

Figure 5. Transmission electron micrographs of the transport phloem of wheat SCI. A, Part of the transport phloem showing the CCs and sieve element. (B) Higher magnification of the area in (A) showing a sieve element with proteoplasts and a structure similar to the longitudinal sieve plate (C) Higher magnification of the area highlighted in (A) showing abundant mitochondria in CCs. (D) D. plasmodesmata between the SE and CC (PPUs). (E) A companion cell containing abundant cellular organelles including mitochondria, endoplasmic reticulum, Golgi apparatus, plastid, vacuole; (F) Magnified micrograph of the pane in (E) CC, companion cell; SE, sieve element; PP, phloem parenchyma cell; Bar: A, $10 \mu \mathrm{m}$; B-F, $1 \mu \mathrm{m}$.
However, the shoot dry weight from anthesis to ripening stage increased 0.435 (23.82\%), 0.432 (23.90\%), 0.514 (30.00\%) and $0.562 \mathrm{~kg} \mathrm{~m}^{-2}(37.15 \%)$ at $10,25,40$ and $55 \mathrm{~mm}$ soil depth, respectively (Table 2); namely, the increase in shoot dry weight at 40 - and 55-mm soil depths were significantly higher than at 10- and 25-mm soil depths.

Grain filling at different seeding depths: At 8 and 16 DAA, the grain mass increased as the seeding depth increased (Fig. $6)$ and the differences in grain mass between these treatments were significant $(P<0.05)$. However, at 24 and 32 DAA, the highest grain masses were observed for $40-\mathrm{mm}$ soil depth, followed by that at 55-, 25- and 10-mm soil depths.

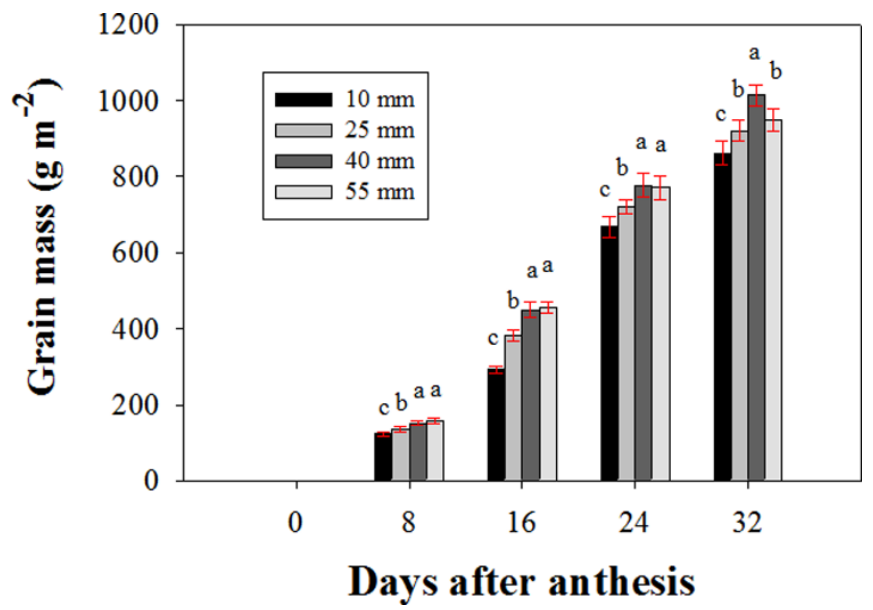

Figure 6. Effect of different seeding depths on grain dry mass $\left(\mathrm{g} \mathrm{m}^{-2}\right)$ during grain-filling. 


\section{DISCUSSION}

Seed sowing at more depth led to extended time needed by the seedlings to push their shoots above the soil surface and thus deep seeding reduces plant number and early vigor which further reduce tiller and spike number (Rebetzke et al., 2007). In wheat, increases in seeding depth resulted in significantly deeper crown placement and delayed seedling emergence (Loeppky et al., 1989; Rebetzke et al., 2007). Therefore, the best seeding depth is needed for crop production. In the present study, we found that as the seeding depth increased up to $40-\mathrm{mm}$ soil depth, the seedling emergence rate and tillering capacity increased, but sharply declined at $55-\mathrm{mm}$ soil depth. The number of spikes per $\mathrm{m}^{2}$ also declined although the fertile tiller percentage significantly higher at $55-\mathrm{mm}$ soil depth than at shallow depth (Table 1). These results are highly consistent with the findings of Rebetzke et al. (2007) who reported that deep seeding resulted in fewer spikes per unit area due to reduced seedling establishment.

As an adaptive response to deep seeding, the SCI of cereal crops such as barley and wheat under deep-seeding conditions elongates to bring the shoot to reach the soil surface from the deep soil (Ashraf and Taylor, 1974; Takahashi et al., 2008). In agreement with these observations the SCI length was found to increase (Fig. 1); however, largely due to the more rapid rate of longitudinal growth, the diameters and wall thickness of SCI xylem vessels decreased (Fig. 2). The differential SCI elongation due to seeding depth was associated with variation in parenchyma cell length because a parallel positive relationship occurred between parenchyma cell length and SCI elongation (Chowdhry and Allan, 1966; Rebetzke et al., 2007).

For the development of SCI, plant hormone may be anticipated as the primary regulators of SCI elongation and transverse expansion. It is well known that gibberellin (GA) influences in stem elongation, a cellular process involving both cell proliferation and cell elongation (Kato et al., 2011). Our study indicates that $\mathrm{GA}_{3}$ was involved in the elongation of SCI as its concentration increased with the increase in seeding depth. Zhao and Wang (2008) suggested that $\mathrm{GA}_{3}$ promoted mesocotyl elongation via cell elongation rather than cell division. Similar work has been reported by Chen et al. (2003). A number of previous studies suggest that a wheat cultivar, 'Hong Mang Mai', shows tolerance to deep-seeding conditions by extreme elongation of the SCI which shows strong sensitivity to $\mathrm{GA}_{3}$ in inducing cell elongation, probably through modification of the expression of $G A-M Y B$ (a transcription factor), the activity of endochitinase (Zhao et al., 2010), increase in the amount of osmotic solute (Chen et al., 2001), enhancement of glucan turnover (Chen et al., 2003) and the uptake of potassium. On the other hand, GA has also been implicated in the cambial proliferation and derivation (Digby and Wareing, 1966). Based on the data above, it is reasonable to postulate that GA might be essential for the development of SCI in wheat.

Cytokinins were found to be involved in the $\mathrm{N}$-status mediated leaf expansion (Dodd and Beveridge, 2006) and in the regulation of the radial growth of plant stem via the development of vascular cambium tissues (Sorce et al., 2013). Generally, the SCI elongation is commonly attributed to the cell elongation rather than the cell proliferation. However, in the present study, we observed significantly higher ZR contents in wheat SCI at 40- and 55-mm soil depth than that at $25-\mathrm{mm}$ soil depth. It could be postulated that cell division is still needed at the middle stages of SCI elongation, but higher cytokinin concentration may be not necessary. This assumption can be strongly supported by the findings that cell division in the cortex and cell expansion in the epidermis are synchronized for the elongation of the SCI and the well-coordinated synchronization results in a rapid elongation of the SCI in wheat (Kato et al., 2011).

The control of xylem cell patterning is of particular interest, because it determines the diameter of xylem vessels, which is central to the efficiency of water and nutrient transport from roots to leaves through the internodes (Sorce et al., 2013). In all developmental processes, cambial activity is finely regulated by hormonal signaling. Auxin is preferentially biosynthesized in the cambial region, where it, along with functions of GA, promotes secondary xylem development (Nilsson et al., 2008) and the elongation of the cambial derivatives to produce xylem vessel and fiber elements (Digby and Wareing, 1966; Dayan et al., 2012). In the present study we found that IAA concentration increases, although not proportionally, with increasing seeding depth and the SCI length. Thus, it could be presumed that the higher SCI IAA concentration in deep-sown wheat probably produce higher activity of radial cambial proliferation.

Present study indicates that SCI ABA content was significantly at $40-\mathrm{mm}(P<0.05)$, or slightly at $55-\mathrm{mm}$ soil depth, higher than that at $25-\mathrm{mm}$ soil depth. Furthermore, we observed that fluridone $(20 \mu \mathrm{m})$ or sodium tungstate $(5 \mathrm{mM})$, two inhibitors of ABA biosynthesis, strongly depressed the SCI elongation in wheat subjected to deep seeding (data not shown). Therefore, we could first time propose that ABA might play an important role in the SCI development in wheat. The sieve element/companion cell complex has an important implication for apoplasmically and symplasmically phloemloading (Slewinski et al., 2013). In the complex, CCs may be more active than surrounding cells in producing energy for nutrient transportation as indicated by a large number of the mitochondria and abundant plasmodesmata linking CC to sieve element there (Fig. 5). The abundant plasmodesmata observed in the present study suggest that the trafficking of macromolecules such as protein (Stadler et al., 2005), sugars (Maule et al., 2011), and RNA (Spiegelman et al., 2013) from $\mathrm{CCs}$ into sieve elements is highly active. However, it is difficult to quantify the differences in the mitochondria 
number per cell and exchanges between CCs and sieve element under TEM. Tissue respiration activity may be used as an indicator of cell physiological activity. Determination of oxygen consumption rate in our study indicates that SCI of wheat under 40-mm depth conditions showed higher respiratory rate and may provide a more favorable environment for energy production, SCI elongation and nutrient transmission than other seeding depth.

The NDVI has been closely associated with physiological parameters and commonly used to assess plant growth (Govaerts et al., 2007). Plant biomass is considered as one of the direct indicators in evaluating the plant growth (Kong et al., 2010). In our experiment, measurement of both parameters suggests that wheat plants raised from shallower seeding grow better than the deeper seeding at the vegetative growth stage. However, the increases in shoot dry weight during grain filling of plants raised from seeds sown at 40and 55-mm depth are significantly higher than 10- and 25mm-sown seeds, indicating that the reduced competition due to lower stand establishment allow plant access to more water, nutrients and light at deep sowing (Photiades and Hadjichristodoulou, 1984; Rebetzke et al., 2007). Shallow seeding (10-25 mm) of winter wheat on Canadian prairies is optimal to maximize yield potential, probably due to better seedling establishment, lower risk of winter damage compared with deep seeding (Loeppky et al., 1989), because deep seeding reduces seedling emergence rate and tillering capacity and thus the spike number, biomass and grain yield (Rebetzke et al., 2007). Whereas under dryland conditions, grain yields increased with seeding depths up to $70 \mathrm{~mm}$ (Yagmur and Kaydan, 2009). The current study has demonstrated that wheat at deeper depths (40- and 55-mm) showed faster grain-filling rate at early stages than at shallower depths (10- and 25-mm). Ultimately, seeding at 40$\mathrm{mm}$ soil depth produced a highest grain yield. These results are contrary to our prediction that the direct nutrient transportation in wheat plants without SCI developed would produce higher yields.

In conclusion, winter wheat sown at $40-\mathrm{mm}$ soil depth could provide better conditions for seed emergence, SCI development and fall tillering capacity. The SCI development may result from the actions of $\mathrm{GA}_{3}$, IAA, ZR and ABA or interactions between them. Although wheat plant growth is better at shallow seeding (10- and 25-mm soil depth) than deeper seeding (40- and 55-mm soil depth), the highest grain yield was obtained in 40-mm-sown wheat plants, immediately followed by that at $55-\mathrm{cm}$ soil depth. The higher grain yields are probably due to the higher grain-filling rate. Therefore, seeding at 40-mm depth may be optimal for winter wheat productivity in northern China.

Acknowledgments: This work was supported by the Shandong and National Earmarked Fund for Modern Agroindustry Technology Research System (SDAIT-01-06 and
CARS-3-1-21), the Special Fund for Agroscientific Research on Public Causes, MOA of China (201303109-7 and 201203079), and the Program of Major Independently Innovative Key Technology of Shandong Province (2014GJJS0201).

\section{REFERENCES}

Ashraf, M. and A.G. Taylor. 1974. Morpho-developmental factors related to winter survival of wheat. I. Association of characteristics of dark grown seedlings and winter survival. Crop Sci. 14:499-502.

Chen, L., A. Higashitani, H. Suge, K. Takeda and H. Takahashi. 2003. Spiral growth and cell wall properties of the gibberellin-treated first internodes in the seedlings of a wheat cultivar tolerant to deep-sowing conditions. Physiol. Plant. 118:147-155.

Chen, L., T. Nishizawa, A. Higashitani, H. Suge, Y. Wakui and K. Takeda. 2001. A variety of wheat tolerant to deepseeding conditions: elongation of the first internode depends on the response to gibberellin and potassium. Plant Cell Environ. 24:469-476.

Chowdhry, A.R. and R.E. Allan. 1966. Culm length and differential development of the coleoptile, root, and subcrown internode of near-isogenic wheat lines. Crop Sci. 6:49-51.

Dayan, J., N. Voronin, F. Gong, T. Sun, P. Hedden, H. Fromm and R. Aloni. 2012. Leaf-induced gibberellin signaling is essential for internode elongation, cambial activity, and fiber differentiation in Tobacco stems. Plant Cell 24:6679.

Digby, J. and P.F. Wareing. 1966. Effect of applied growth hormones on cambial division and differentiation of cambial derivatives. Ann. Bot. 30:539-548.

Dodd, I.C. and C.A. Beveridge. 2006. Xylem-borne cytokinins: still in search of a role? J. Exp. Bot. 57:1-4.

Govaerts, B., N. Verhulst, K.D. Sayre, P. De Corte, B. Goudeseune, K. Lichter, J. Crossa, J. Deckers and L. Dendooven. 2007. Evaluating spatial within plot crop variability for different management practices with an optical sensor? Plant Soil 299:29-42.

Hoffmann-Benning, S. and H. Kende. 1992. On the role of abscisic acid and gibberellin in the regulation of growth in rice. Plant Physiol. 99:1156-1161.

Huang, B. and H.M. Taylor. 1993. Morphological development and anatomical features of wheat seedlings as influenced by temperature and seeding depth. Crop Sci. 33:1269-1273.

Irvine, R.B. and M.C. Therrien. 1985. Effective xylem radius of the subcrown internode of barley (Hordeum vulgare L.). Can. J. Plant Sci. 651:211-214.

Kato, F., M. Araki, Y. Miyazawa, N. Fujii, K. Takeda, H. Suge and H. Takahashi. 2011. Factors responsible for deep-sowing tolerance in wheat seedlings: varietal 
differences in cell proliferation and the co-ordinated synchronization of epidermal cell expansion and cortical cell division for the gibberellin-mediated elongation of first internodes. Ann. Bot. 108:439-447.

Kende, H., E. Van Der Knaap and H.T. Cho. 1998. Deepwater rice: a model plant to study stem elongation. Plant Physiol. 118:1105-1110.

Kong, L.A., F. Wang, B. Feng, S. Li, J. Si and B. Zhang. 2010. A root-zone soil regime of wheat: physiological and growth responses to furrow irrigation in raised bed planting in northern China. Agron. J. 102:154-162.

Loeppky, H., G.P. Lafond and D.B. Fowler. 1989. Seeding depth in relation to plant development, winter survival, and yield of no-till winter wheat. Agron. J. 81:125-129.

Maule, A.J., Y. Benitez-Alfonso and C. Faulkner. 2011. Plasmodesmata- membrane tunnels with attitude. Curr. Opin. Plant Biol. 14:683-690.

Mulholland, B.J., B. Taylor, C.R. Black and J.A. Roberts. 1996. Effect of soil compaction on barley (Hordeum vulgare L.) growth. II. Are increased xylem sap ABA concentrations involved in maintaining leaf expansion in compacted soils? J. Exp. Bot. 47:551-556.

Munns, R. and R.E. Sharp. 1993. Involvement of abscisic acid in controlling plant growth in soil of low water potential. Aust. J. Plant Physiol. 20:425-437.

Nilsson, J., A. Karlberg, H. Antti, M. Lopez-Vernaza, E. Mellerowicz, C. Perrot-Rechenmann, G. Sandberg and R.P. Bhalerao. 2008. Dissecting the molecular basis of the regulation of wood formation by auxin in hybrid aspen. Plant Cell 20:843-855.

Nishizawa, T., H. Suge, A. Higashitani and H. Takahashi. 1998. The relationship of the ethylene responsiveness to the varietal differences in the deep-seeding tolerance of wheat. Tohoku J. Crop Sci. 41:57-59.

Photiades, J. and A. Hadjichristodoulou. 1984. Sowing date, sowing depth, seed rate and row spacing of wheat and barley under dryland conditions. Field Crops Res. 9:151162.

Rebetzke, G.J., R.A. Richards, N.A. Fettell, M. Long, A.G. Condon, R.I. Forrester and T.L. Botwright. 2007. Genotypic increases in coleoptile length improves stand establishment, vigour and grain yield of deep-sown wheat. Field Crops Res. 100:10-23.

Redmann, R.E. and M.Q. Qi. 1992. Impacts of seeding depth on emergence and seedling structure in eight perennial grasses. Can. J. Bot. 70:133-139.
Schillinger, W.F., E. Donaldson, R.E. Allan and S.S. Jones 1998. Winter wheat seedling emergence from deep sowing depths. Agron. J. 90:582-586.

Slewinski, T.L, C. Zhang and R. Turgeon. 2013. Structural and functional heterogeneity in phloem loading and transport. Front. Plant Sci. 4:244. doi: 10.3389/fpls.2013.00244.

Sorce, C., A. Giovannelli, L. Sebastiani and T. Anfodillo. 2013. Hormonal signals involved in the regulation of cambial activity, xylogenesis and vessel patterning in trees. Plant Cell Rep. 32:885-898.

Spiegelman, Z., G. Golan and S. Wolf. 2013. Don't kill the messenger: Long-distance trafficking of mRNA molecules. Plant Sci. 213:1-8.

Stadler, R., K.M. Wright, C. Lauterbach, G. Amon, M. Gahrtz, A. Feuerstein, K.J. Oparka and N. Sauer. 2005. Expression of GFP-fusions in Arabidopsis companion cells reveals non-specific protein trafficking into sieve elements and identifies a novel post-phloem domain in roots. Plant J. 41:319-331.

Suge, H., T. Nishizawa, H. Takahashi and K. Takeda. 1997. Phenotypic plasticity of internode elongation stimulated by deep seeding and ethylene in wheat seedlings. Plant Cell Environ. 20:961-964.

Takahashi, H., M. Noda, K. Sakurai, A. Watanabe, H. Akagi, K. Sato and K. Takeda. 2008. QTLs in barley controlling seedling elongation of deep-sown seeds. Euphytica 164:761-768.

Takeda, K. and H. Takahashi. 1999. Varietal variation for the deep-seeding tolerance in barley and wheat. Breed Res. $1: 1-8$.

Yagmur, M. and D. Kaydan. 2009. The effects of different sowing depth on grain yield and some grain yield components in wheat (Triticum aestivum L.) cultivars under dryland conditions. Afr. J. Biotechnol. 8:196-201.

Yang, J.C., J.H. Zhang, Z.Q. Wang, Q.S. Zhu and W. Wang. 2001. Hormonal changes in the grains of rice subjected to water stress during grain filling. Plant Physiol. 127:315-323.

Zhao, G., J. Fu, G. Wang, P. Ma, L. Wu and J. Wang. 2010. Gibberellin-induced mesocotyl elongation in deepsowing tolerant maize inbred line 3681-4. Plant Breed. 129:87-91.

Zhao, G. and J. Wang. 2008. Effect of gibberellin and uniconazole on mesocotyl elongation of dark-grown maize under different seeding depths. Plant Prod. Sci. 11:423-429. 